Brit. J. vener. Dis. (1966), 42, 58.

\title{
INTERNATIONAL UNION AGAINST THE VENEREAL DISEASES AND TREPONEMATOSES
}

\author{
GENERAL ASSEMBLY, 1965
}

The General Assembly of the International Union against the Venereal Diseases and Treponematoses was held in Lisbon at the Institute of Tropical Medicine on April 29, 1965.

\section{Opening of the Meeting}

The President, $\mathrm{Mr}$ Ambrose King, welcomed the delegates and observers participating in the Assembly, which had been called to discuss the programme of the Union and to suggest ways of implementing the decisions reached during the technical conference before the next General Assembly convened in 1967.

The conference just concluded had been very successful, and the President thanked the speakers for the high qualify of their reports and the members who had taken part in the discussions. He felt certain that, on returning to their respective countries, all who attended the Conference would tell their colleagues about the work of the Union and ask for greater support to enable it to improve and extend its work. The Executive Committee had approved a third category of members, "Individual Associate Members", whose annual subscription would amount to only $\$ 3$. This new group was to include nonmedical personnel concerned with the work of the Union: social workers, health educators, public health auxiliary workers, and so on; he felt sure that this would substantially increase the numbers of those supporting the activities of the Union.

Before proceeding with the agenda, the President thanked their Portuguese colleagues, who had worked hard and efficiently to make the Conference such an undoubted success. The kindness, hospitality, and generosity of their hosts had been beyond praise; particular thanks were also due to the Ladies Committee, who had organized a delightful programme of visits and entertainment.

Mr King also thanked the representatives of WHO who had attended the Conference (Dr T. Guthe, Dr J. Burton, and Dr N. Radovanovic); the Union greatly appreciated their help, and this appreciation would be conveyed both to them personally, and also to the Director-General of WHO and to the Director of the WHO Regional Office for Europe.
Finally, he thanked the officers of the Union, namely Prof. Canaperia, the most efficient Secretary-General, the two assistant Secretaries-General, Mrs Tuller and Dr Perdrup, and the Treasurer, Dr. Tassi, who had unfortunately been unable to be present.

The President then asked Prof. Canaperia, Mrs Tuller, and Dr Perdrup to present their reports.

\section{Report of the Secretary-General, Prof. G. A. Canaperia}

This Report covers a period of almost 3 years (September, 1962, to April, 1965), during which the Executive Committee has held four meetings: in Washington in September, 1962; in Copenhagen in June 1963; in Paris, in April, 1964; and finally at Lisbon, just before the opening of this Assembly in April, 1965.

I wish to thank our President, Mr King, our VicePresidents, and the Counsellors of the Union, who advised and supported me in the decisions I have had to take in my capacity of Secretary-General.

Publications.-The Proceedings of the Washington General Assembly were published in 1963 and were distributed to all members of the Union.

The Proceedings of the "World Forum on Syphilis and Other Treponematoses" were published by the United States Public Health Service and sent to all participants. A certain number of copies were put at the disposal of the Union by the kindness of Dr William Brown, President of the Organizing Committee of the Conference, who I wish now to thank; and these were distributed by the Secretariat to members who had been unable to participate in the Washington meeting.

The Bulletin of the Union, the publication of which was discussed at the last Assembly, came into being thanks to the kindness of the British Journal of Venereal Diseases, and of its Editor, Dr S. M. Laird, whom I here wish to thank most warmly for his valuable collaboration. Three Bulletins have appeared so far in the two official languages of the Union, in 1963,1964, and 1965, and have been distributed to all our members. We hope to be able to continue this publication regularly, to strengthen ties and maintain close communication with our members between the official meetings. We shall be happy if our members will send us information, comments, and 
suggestions, for inclusion in the Bulletin, thus increasing its interest and importance.

The Proceedings of the meetings of the Executive Committee, in Washington, Copenhagen, and Paris were published in the Bulletin, and the New Statutes approved by the General Assembly in Washington were also printed in English and French and distributed; some copies are still available at the Secretariat, and will be sent to members on request.

Finally, in order to facilitate the recruitment of new members and to make known the aims and the activities of the Union, the Secretariat has prepared a brochure in French and in English which has also been widely distributed.

Liaison with Other Organizations.-Close and friendly relations have been maintained with the United Nations Agencies and with other non-governmental organizations working in similar or related fields. Our collaboration with WHO and more especially with the VD and Treponematoses Section has been continuous and fruitful and I thank Dr T. Guthe and his collaborators for their neverfailing assistance and interest.

One of the many ways in which we have collaborated with WHO relates to a problem regarded as of first priority during the last Assembly, namely the professional training of doctors in venereology, an indispensable prerequisite for our success.

On this subject the Union contributed to technical discussions during the XVI World Health Assembly in 1963 on the professional training of doctors in the preventive and social aspects of medical practice, and a report prepared by Dr Curtis (UK) on specific problems of the teaching of venereology was presented.

During the same World Health Assembly, at which the Union was represented by Dr Tassi and myself, a statement on the activities and programme of the Union was presented and as part of the discussion of the technical programme of WHO, this was published in our Bulletin in 1963. The President, Mr King, prepared a memorandum on "Venereal Disease Problems and Adolescent Health" for the WHO Expert Committee on the Health Problems of Adolescence which met in Geneva on November 3 to 9. 1964. WHO has sponsored and supplied technical and financial assistance for a study jointly undertaken on the teaching of venereal diseases and treponematoses in medical schools and at post-graduate level. A preliminary report on this study has been presented at this Conference by Dr Webster (USA). A questionnaire prepared in collaboration with WHO was sent out to 750 medical schools and schools of public health in 87 countries, and the response, as you have heard, was very satisfactory. I wish to thank our colleagues of WHO who collaborated in this study and most particularly Dr Guthe and Dr Gregorzweski, chief of the Division for Professional Information at WHO. Special thanks are due to Dr Webster who undertook the heavy task of preparing and presenting the report, and to our Regional Director for the Americas, Mrs Tuller, and her colleagues at the ASHA, who distributed the questionnaire, collected the answers and translated and tabulated the relevant data.
The Executive Board of WHO at its XXXIVth session in May, 1964, reviewed the programme concerning endemic treponematoses in childhood, venereal syphilis, and gonococcal infections. Dr Guthe presented an excellent report on the subject and the Secretariat of the Union prepared a paper for presentation by Dr Tassi. An interesting discussion followed and the Executive Board approved a resolution (E.B. 34/R/25) which noted with satisfaction the activities of WHO in the field of venereal diseases and treponematoses and urged member states to maintain adequate and effective measures to reduce the incidence of endemic treponematoses, particularly in children, and to increase their efforts to combat the recrudescence of venereal infections. Member states were requested to report the extent of their present programmes and their plans to achieve these objectives.

Liaison with the United Nations Economic and Social Council (UNESCO) has been maintained by our Regional office for the Americas, and Mrs Tuller will tell you more about this.

Our close collaboration with UNICEF must also be mentioned. Mrs Tuller was appointed President of a Committee of non-governmental organizations in liaison with UNICEF intended to co-ordinate all efforts for assistance to developing countries. Mrs Tuller and her collaborators, particularly Miss Gonzales, have done wonders in making the aims and work of the Union better known in the Americas, and I ask them to transmit our grateful thanks to the ASHA for its constant and generous help over many years to our Regional Office in New York and to the Union in general.

Our Regional Office for Europe in Copenhagen, under the direction of Dr Perdrup, has maintained close liaison with the WHO Regional Office for Europe. Dr Perdrup will tell you himself about the activities of his office, I merely wish to thank him for his valuable help.

Representatives of the Union.-During the last 3 years the Union has been regularly represented at the World Health Assemblies as well as at the numerous meetings of the WHO Executive Committee in Geneva, and has also contributed to a number of WHO technical meetings. Dr P. Durel represented the Union at the Expert Committee on Gonococcal Infections in Geneva in 1962, and Drs King, Perdrup, and Tottie were present at the European Seminar on VD organized by WHO in Stockholm in 1963.

The Union was also represented at meetings of the WHO Regional Offices: Mrs Tuller and Miss Gonzales participated in the meetings of the Regional Office for the Americas, Dr Tottie represented the Union at the meeting of the Regional Office for Europe in Stockholm in 1963, and I represented it in Prague in 1964.

Dr Pierra Vejabul was present, on behalf of the Union, at the meeting of the Regional Office for south-east Asia in Bangkok in 1964, and Prof. A. Basset has maintained liaison with the Regional Office for Africa.

We have also tried to have the Union represented at major meetings of the international non-governmental organizations, whose work in fields of social welfare and health are similar to our own. Mrs Force of the ASHA 
represented the Union at the Conference of the International Union of Family Organizations in Rio de Janeiro in 1963, and presented a very interesting report on "The Role of School in Education for Family Life". Dr Tassi represented the Union at the International Conference of non-governmental organizations in Rome in 1964, and I myself was able to keep in close touch with the International Union for Health Education by participating in numerous meetings of the Directing Board. We have had the pleasure of welcoming here Dr Aujoulat, Secretary-General of that Union.

Finally, liaison was also maintained with the Council of International Organizations of Medical Sciences, of which the Union is a member and which has always given us help, including financial assistance at technical Conferences. I myself attended the CIOMS General Assembly in Brussels in 1964, as well as several meetings of their Directing Board, during the last of which I was asked to represent the CIOMS at this Assembly.

We have kept up this policy of active participation at the meetings of organizations with common interests, but our financial situation does not permit us to contribute towards the expenses of our representatives, and I therefore wish to record the gratitude of the Union to those who have so generously taken part in this work.

Recruitment.-We have continued our recruiting campaign and have sent out many letters and brochures to make our existence and our work known to those who might support us. The number of Member-Associations or Group-Members has increased by three (Spain, Eire, and Senegal), and we are in correspondence with representatives of Hungary and the Lebanon in the hope that they will join as effective members.

The number of individual members is still very smallonly 26. Dr Perdrup has made a suggestion, supported by our President, which will be discussed by the Assemblyto establish a further category of "associate individual members" paying a reduced membership fee. This would enable us to collaborate with non-medical personnel concerned in the control of VD; such support would do much to assist our activities.

Statutes and By-Laws.-The new Statutes of the Union, prepared by the Secretariat and submitted to the Executive Committee, were approved by the last Assembly in Washington, with a few minor formal amendments.

Copies of the by-laws having been distributed to all participants, I will draw the attention of the Assembly to two points:

(1) Article 1 contemplates two categories of effective members: National Organizations (including Health Administrations) and Individual Members, each of the former being entitled to twenty votes, and the latter to one. In this way the voting rights of individual members have been established and a balance struck between the two categories.

(2) Article 5 deals with the problem of the Regional Offices; there are two at present-and very active they are-one for Europe and one for the Americas. It has not yet been possible to establish Regional Offices in other parts of the world, and we have therefore envisaged the possibility of appointing "zone representatives" to ensure liaison between the "zone" and the Secretary-General and to promote new support for the Union. This may be considered a first step towards the creation of more Regional Offices, when circumstances permit.

Lisbon Conference.-Our activities of the last few months have been mainly concerned with the preparations for the present Conference. We have worked in close and friendly collaboration with our colleagues of the Portuguese Organizing Committee, and I wish to express our deep appreciation and to thank them all, especially their President, Dr Norton Brandão, their Vice-President, Dr da Fonseca, and their most capable and diligent Secretary-General, Dr Da Cruz Sobral. Having had the pleasure of following their work very closely, I know what exertions they have made in providing such an efficient organization in these wonderful surroundings in which the work of the Conference has proceeded so smoothly. Their arrangements and their kind hospitality have been most admirable and to them is due credit for the success of our proceedings.

\section{Report of the Regional Director for the Americas, Mrs Josephine Tuller}

The Regional Office for the Americas wishes to express its gratitude to the American Social Health Association for its sponsorship of our programme for a period of almost 20 years. We are indeed fortunate that the Association has been led by persons of broad vision who recognize the potential and importance of international efforts and who encourage and support us in the Americas.

In considering our activities since the last General Assembly in 1962, we have always before us the assignment of developing Union programmes in the Americas. I shall dwell upon this phase of our work in some detail, because it is indeed our greatest challenge and our most difficult task. I remind you that in the Americas the concept of the voluntary agency is still somewhat under suspicion and the venereal diseases and prostitution are unpopular subjects for discussion. However, in the last year, we have been able to take advantage of several encouraging opportunities. This makes us think that we are finding a new way of doing things which need to be done, a new approach, a "breakthrough", if you please.

We have been fortunate in the assignment of a Latin American to our staff, a native of Peru and an enthusiast whose talents fit well into our programme and especially into the following assignment which has come our way. At the United Nations headquarters (where, you will remember, we have the responsibility of liaison duties for the Union), the Executive Board of UNICEF requested the help of its Non-Governmental Organization Committee to promote co-ordinated efforts on behalf of UNICEF in developing countries. Specifically, this meant a project of organizing a council of voluntary agencies in Peru, which would assist the Government in planning for children and youth in its overall national plans. I was made Chairman of a Committee for this purpose, and 
Lili Gonzales, my Assistant, made two trips to Lima and organized a council of voluntary organizations called COVSAN (Council of Voluntary Agencies to the Service of Children and the Family). Her success has had publicity in Peru, at the United Nations, and among other international non-governmental agencies. As this project goes forward, it is seen as a pattern for other Latin American countries.

The significance of this project to the Union is that not only are we fulfilling our obligations of contributing to UNICEF (in which we so strongly believe), to a country in our own Region, to the non-governmental organization movement in Latin America, but we are also joining the tide of changing trends where united effort is the key to progress.

Furthermore, throughout this whole project, the name of the Union has been identified with these important activities. Contacts made in preparation for the project, at the United Nations, in Washington with the PanAmerican Health Organization, the Alliance for Progress, the Peace Corps, and many other international organizations working in the Americas, have given recognition to the Union and its programme. In other words, this project has "made friends and influenced people" in a region where the going has been hard in the past-with no field service and a challenging programme subject. In pursuing this assignment we are following the sage advice of one member of our Advisory Committee who, returning from Latin America some years ago, emphasized the importance of "continuing to sow seeds and to take maximum advantage of every opportunity to secure interest" and that "an effective project in one Latin American country would have constructive reaction in other Latin American countries". It is our firm belief that these reminders of our existence to top leadership in other countries and in the United States do bring prestige and recognition to the Union, and we consider these a first step toward support of our programme in America.

I will give a brief summary of some of the more outstanding activities of the Regional Office for the Americas, such as distribution of material, participation in international meetings, participation in research, consultation with leaders from other countries, liaison at the United Nations headquarters, etc. A detailed report of all these activities is given on a separate sheet which is available at this meeting.

\section{Distribution of Material}

3,194 pieces of Union maierial as well as material of the American Social Health Association.

475 copies of the 1964 Joint Statement to 78 countries. The Joint Statement is the ASHA's annual VD report, which contains an international section.

200 copies of the 1963 IUVDT Bulletin.

788 copies of UNICEF publications.

200 (and more) items of WHO material.

Translations.-Publications in English and Spanish are continuously being translated by staff in our office, with special emphasis, of course, on translations into Spanish of material for distribution in the Americas. For example: (a) 7-page summary of the 1963 IUVDT Bulletin. (b) "VD: Wrong Prognosis"-article from WHO Chronicle for April, 1964.

(c) Questionnaire and covering letter for the recent WHO-IUVDT contract on the teaching of venereology survey.

Field Services.-Miss Lili Gonzales' report on her first trip to Peru was mailed to all of you and distributed at the Executive Committee meeting in Paris in June, 1964. Her second report is now available at this meeting.

Research.-As a result of a recommendation of the Union and a deep interest on the part of the World Health Organization, a contract was signed by the Union and the WHO to send a questionnaire with a covering letter to 750 medical and public health schools in 87 countries, asking about the teaching of venereology at graduate and post-graduate levels. Dr Bruce Webster is the Research Consultant for this project, and the staff of the Regional Office for the Americas and staff of the American Social Health Association have handled the translations, clerical, and secretarial work, and the preliminary tabulation. The preliminary findings of this survey have been presented by Dr Webster, and it is proposed to carry on with the investigation.

Consultation.-During 1964, nineteen distinguished representatives in the fields of medicine, public health, social sciences and others have visited the New York office from the following countries: Australia, Chile, Colombia, England, France, India, Iraq, Japan, Peru, Spain, and the United States of America.

At this point I would like to bring to your attention the Pan-American Health Organization Newsletter of January, 1965, which contained an article on the VD discussion which took place at the PAHO meeting in Mexico City in September, 1964. I quote this because it offers guidelines for future programmes and urges intensification of both the official and voluntary programmes in the field of VD control; it also, I regret to say, indicates how little progress has been made in this region.

Venereal diseases are rapidly becoming a serious public health problem in Latin America. But the extent of the diseases' prevalence is not known accurately.

In many cases VD sufferers prefer to resort to self-medication, or to treatment by persons other than qualified doctors, according to a report presented to health officials. Even when treated by physicians or in medical institutions, far too often cases are not reported.

Those who do register are "only a meagre proportion", the report says, of the total number afflicted.

Cited as reason for the rising trend of VD is the "greatly increased mobility and migration, as well as an apparent increase in sexual promiscuity" among populations.

To check the spread of VD, the report calls upon those nations of the hemisphere with control programmes to intensify them, and upon others to begin them.

As another counter-measure, the report urges better health education to provide the population 
with more "knowledge of venereal diseases, their dangers, and their prevention".

A Pan-American seminar on VD control is to be held in 1966 in the United States.

In considering our work in the Americas during these past 3 years, we have several comments to make which we would like to share with you to-day.

First, some observations on the World Forum on Syphilis and Other Treponematoses which, you will remember, took place in Washington in 1962, at the time of our last General Assembly, and for which we had the responsibility of developing the behavioural science section. We found that the greatest obstacle in recruiting speakers for this section lay in the fact that so few of the prospective participants-anthropologists, psychologists, sociologists, psychiatrists, educators, etc.--had related their research to the psychosocio-cultural factors leading to VD. Many whom we invited supported our effort but declined to participate, pleading lack of information in their studies with regard to the relationship between behavioural factors and VD. This does underline the fact that VD has been a problem relegated to professionals in the public health field, its behavioural aspect having been heretofore largely ignored.

We sincerely hoped that the emphasis which the Union gave in its participation in this section of the World Forum programme would bear fruit. I can report that our office has had many more requests for assistance in this field since the Forum. And the United States Public Health Service, as Dr Brown, Chief of the Venereal Disease Branch, will tell you, has added to their staff a social scientist who is charged with initiating studies which will bring to light existing knowledge in this field. Is not this progress?

Secondly, we are becoming increasingly sensitive to the importance of co-ordinated effort in programme development as well as the inter-relationships of the medical and behavioural sciences. In our Regional programme this awareness is being translated into action by giving assistance to activities which have important consequences to our programme. With the world so small today, we cannot pursue with any success an isolated programme, and we should not try to do so, particularly in the field in which we are working.

In closing, I wish to thank you for a memorable week. I express my deep appreciation to our hosts, Dr Brandão, Dr. Fonseca, Dr Sobral, and their hard working staff, for an assignment well done. I wish to say to my colleagues, which means all of you, that the reminder that we are all working together is a great strength and inspiration to us in the Americas.

\section{Report of the Regional Director for Europe, Dr Axel Perdrup}

Since the Executive Committee Meeting in Paris in April, 1964, I have been engaged on an assignment as WHO short-term consultant to Thailand, to advise on organizing the campaign against VD. The size of the problem is illustrated by the fact that, in a population of 30 million people, 15 per cent. are sero-reactors. Clinics and laboratories were visited all over the country and a report was submitted to WHO with appropriate recommendations.

The next problem in which I was involved was related to the prevalence of gonorrhoea in Greenland. It was reported that the disease was most common in unmarried persons aged between 16 to 29 years, and it was therefore decided to give repeated preventive treatment to this group. There was, however, some difference of opinion whether such treatment should be given compulsorily or offered for voluntary acceptance. I argued that in such situations the approach should be based upon the provision of sufficient and clear information to the group in question, and that each individual should be free in principle to choose prophylactic treatment or to reject it if he was fully satisfied that he had not been exposed to the risk of infection.

In the past months I have lectured to general practitioners in the provinces of Denmark and have tried to learn something about their attitude towards the management of VD. One of the most important facts which emerged was that gynaecologists seem to rely upon instinct and revelation in deciding which patients to examine for gonorrhoea and which not.

Apart from this the Regional office for Europe has dealt mainly with routine correspondence concerning the various activities of the Union including this General Assembly. One problem is that some people wish to become associate members of the Union but find that a subscription of $\$ 10$ per year is too expensive when paid in addition to subscriptions to their ordinary scientific and professional societies and organizations. May I therefore suggest that the General Assembly gives favourable consideration to the suggestion of establishing relationships with interested and useful persons at a reduced subscription.

The President thanked Prof. Canaperia, Mrs Tuller, and Dr Perdrup for their reports, and asked the Assembly for any comments or questions.

DR Solamito wished to draw attention to Item 1 of the By-laws, which fixed the number of votes for Member Organizations (20) and for Individual Members (1); he pointed out that a difficult situation might arise if the number of individual members in one country were so large as to nullify the decisions of the National Association. He felt it might perhaps be wise to limit the total number of votes for individual members in every country.

Mr KING thanked Dr Solamito for his remark and pointed out that this question would be discussed under Item VIII of the Agenda.

The Assembly then approved the three reports and Mr King went on to ask Prof. Canaperia-in the absence of Dr Tassi-to deliver the Treasurer's Report.

\section{Report of the Treasurer}

I wish first of all to express Dr Tassi's regret at his absence, which is due to an important mission abroad. His report, which covers the financial years $1962-3-4$, has 
been distributed to all participants in the two official languages of the Union.

Following the instructions given at the previous Assembly, the debt to the publishers Masson for printing the volume on "Non-Gonococcal Urethritis" has been settled, and the arrears of contributions and assets which had proved impossible to collect have been written off, so that the last two budgets, for the years 1963 and 1964 , are more realistic and reflect the actual financial situation of the Union.

The following detailed considerations of the budget for 1964 can also be applied to the previous budgets.

The total income, when all active members have paid their contributions, should amount to $2,484,106$ Italian lire (about $\$ 4,000$ ), including the $\$ 1,200$ received as special contributions. Expenditure was approximately $\$ 3,000$, including the cost to the Regional Office of New York of the study of the teaching of venereology in medical schools.

The detailed figures (p. 15 in the French text and p. 31 in the English text) show that the total arrears of contributions on December 31, 1964, amounted to approximately $\$ 2,300$. Two Member Organizations have not paid their contribution since 1960 and another since 1961-these are the Gaffre and Guinle Foundation of Brazil, the Japanese Society for the Prevention of Venereal Diseases, and the Costa Rican Ministry of Health. The Executive Committee, acting on a suggestion put forward by the Assembly, decided that those which had not paid their dues for the last 3 years, should be suspended from membership but the Secretary-General was allowed a certain discretion in applying this regulation. We understand that these three organizations are facing financial difficulties but hope to be able to pay their contributions in the near future, and for this reason they still appear in the list of members.

Under the item "Income" we have the contributions of Member Organizations (a total of approximately $\$ 2,500$ ) but only ten out of our 26 individual members have so far paid their contributions for 1964 (a total of $\$ 100$ ).

We have, however, received a special contribution of $\$ 200$ from the firm of SPECIA in Paris, a grant of $\$ 500$ from WHO for the study on the teaching of venereology in medical schools, and one of $\$ 500$ from CIOMS towards the expenditure involved in publishing the Proceedings of this Conference.

The financial situation of the Union may thus be considered fairly satisfactory. It is true that our resources are modest and that we have to maintain very strict economy in order to be able to carry out our technical programme of Conferences and Assemblies.

Your Treasurer wishes to stress that fund-raising and collecting regular contributions from all members is a difficult matter, so that we need the co-operation and support of all our members and friends in all countries.

Mr King thanked the Secretary-General and the Treasurer for their excellent work, and the Assembly approved the financial report for the years 1962 to $64 .^{*}$

* The detailed report of the Treasurer has been published separately and distributed to all members; those wishing to have more copies should apply to the Secretary-General.

\section{Programme of Work, 1965-67}

The President recalled that this was discussed by the Executive Committee and would be presented to the Assembly in the form of resolutions, to be considered under Item $X$ of the Agenda. At this point he only wished to mention that "Health Education in VD Control" had been recommended as one of the main subjects of the next Conference, and to this the Assembly agreed.

\section{Membership of the Union}

The President stated that besides the two categories of members already existing-national associations with twenty votes and individual members with one vote - the possibility had been suggested of creating a further category of "Individual Members", paying a reduced fee and having no voting rights. There were no comments and $\mathrm{Mr}$ King concluded that the Assembly agreed to this proposal.

\section{By-Laws}

The President stated that, after the adoption of the new Statutes by the last Assembly, the SecretaryGeneral had prepared a draft of the By-Laws, which had been examined by the Executive Committee, and approved with some minor amendments.

Referring to Dr Solamito's question regarding Article 1 of the By-Laws (above, p. 62), Prof. Canaperia stated that this matter had been discussed at length by the Executive Committee, it was felt that the possibility of reversing the balance of votes between National Associations and individual members from the same country was very remote. In fact, there were at present only 26 individual members from various countries and only three of them were present at the Assembly; only if the number of individual members greatly increased, might it be necessary to modify the By-Laws to cover the point raised by Dr Solamito.

There were no further comments and the revised By-Laws were then adopted.

Mr King stated that copies of the new Statutes and By-Laws would be distributed to all members of the Union.

\section{Publications}

The President recalled that the Bulletin of the Union had been published regularly in the British Journal of Venereal Diseases, and that copies had been sent to all members. He asked the Assembly for comments and suggestions.

DR P. Durel (Paris) stated that the French journal Prophylaxie Sanitaire et Morale regularly published brief summaries of proceedings of meetings of the Union; he had recently been told that it 
might be possible to increase this section and that a complete text of the proceedings could be published, as in the British Journal of Venereal Diseases.

Mr King thanked Dr Durel and, noting that there were no further comments, passed to the next item.

\section{Resolutions}

The President stated that the Executive Committee had approved certain resolutions to be presented to the Assembly.

(1) DR BRUCE WeBster read and moved the adoption of the first resolution:

The Twenty-fourth General Assembly of the IUVDT.

\section{CONSIDERING}

(i) The significant recrudescence of venereal infections reported throughout the world in recent years;

(ii) The outcome of the preliminary world-wide study of medical education and training in venereology and VD control undertaken by the Union in co-operation with the World Health Organization;

(iii) The need for intensified activities in many countries in this field.

\section{RECOMMENDS}

(i) That the study of medical education in venereology and VD control be continued by the Union, in cooperation with WHO, with a view to further evaluation;

(ii) That the possibility be explored of arranging discussions of this problem with medical schools of developing and developed countries in different regions;

(iii) That a report on further developments in this matter be presented to the next general Assembly of the Union.

Dr P. Durel and Prof. A. Basset, commenting on the situation in France, noted that in recent years certain countries had greatly reduced the teaching of venereology in the professional training of doctors, social workers, and nurses; they stressed the necessity for re-establishing or increasing training in the subject. They seconded the resolution.

Dr Hasselmann also seconded the resolution with a minor drafting amendment.

The resolution was approved.

(2) DR C. S. Nicol read and moved the adoption of the following resolution:

The Twenty-fourth General Assembly of the IUVDT.

\section{WELCOMES}

The broadening interest in sociological, behaviouristic, educational, and related research in venereal diseases and treponematoses as manifested in several of the studies which had been presented for discussion;

\section{Notes}

The need to continue research in epidemiology and to apply epidemiological methods more vigorously;

(a) Against venereal diseases which show a significant world-wide upward trend, in spite of which, in some instances, only inadequate efforts are made at contact-tracing within and between countries, thus permitting cases of transmissible infection to remain untreated in the populations concerned;

(b) Against the non-venereal treponematoses, particularly yaws and endemic syphilis, so as to reduce further prevalence of these conditions in developing tropical and sub-tropical countries, following mass campaigns for the administration of penicillin in recent years;

\section{RECOMMENDS}

(i) That more basic research be undertaken in the microbiology, biochemistry and immunology of the treponematoses and that active steps should be taken to exchange full information with those working in other fields of investigation.

(ii) That intensified efforts be made to grow $T$. pallidum in vitro and that further investigation be undertaken on protective immunity, possibly leading to better public health methods for the control of treponemal diseases;

(iii) That more basic research on gonorrhoea and related diseases should also be undertaken.

Drs P. Durel and M. Tottie seconded the resolution. Dr T. Guthe also gave warm support to the principles of this resolution, it must be stressed that contact-tracing could not be limited within one country but must be undertaken, when necessary, also between countries. Migrants, travellers, and workers, who move from one country to another, especially in the interchanges between members of the Common Markets, make it essential to consider VD control as an international problem. And, speaking of Common Markets, it could be said that there certainly was one Common Market in the world which functioned well-the Common Market of syphilis.

\section{Election of Officers}

Mr King recalled that the Executive Committee of the Union had always been, traditionally, the nominating committee, and gave details to the Assembly of the list of officers recommended by the Committee:

President:

Honorary President:

Secretary-General: Assistant SecretariesGeneral:

Vice-Presidents:
Mr Ambrose King (UK)

Dr André Cavaillon (France)

Prof. Giovanni A. Canaperia (Italy)

Dr Axel Perdrup (Denmark) Mrs Josephine Tuller (USA)

Dr Brun Pedersen (Denmark)

Dr Pierre Durel (France)

Dr Claude Nicol (UK)

Dr Malcolm Tottie (Sweden)

Dr Bruce Webster (USA) 
Technical Counsellors: Dr William Brown (USA)

Dr Antonio Campos Salas (Mexico)

Prof. A. Basset (France)

Dr Carlos Julio Alarcon

Dr John Cutler (USA)

(Venezuela)

Dr Francisco Norton Brandão

Dr P. N. Rangiah (India)

(Portugal)

Prof. Jozef Towpik (Poland)

Dr Pierra Vejjabul (Thailand)

Treasurer: $\quad$ Dr Goffredo Tassi (Italy)

Legal Adviser: $\quad$ Maître J. Pfeiffer (France)

Mr King stated that the Executive Committee, in proposing the list, had two ideas in mind: to assure full representation of the National Associations which were members of the Union, and to suggest names of persons who had always given full and active support to the Union.

It was felt desirable for the President and the Secretary-General to maintain their posts for the next 2 years, till the General Assembly of 1967, when it would be necessary to recommend changes in these appointments.

It was also felt that some important countries had no representation in the Executive Committee, and the President asked the Assembly to empower the Executive Committee to add to the list some names of technical counsellors, after the necessary inquiries had been made.

Dr. Hesse suggested the name of Dr Hasselmann for inclusion among those of the technical counsellors.

The Assembly felt that a representative from Germany should be included in the Executive Committee, or even two, if it were possible to have representation from West and East Germany, but it would be difficult to make an appointment at the present time without consulting the National Associations concerned, which were not at present active members of the Union.

The Assembly agreed that the best solution was the one proposed by the President and gave the Executive Committee authority to select appropriate Technical Counsellors and to appoint them in due time.
The Assembly gave unanimous approval to the list of appointments and full authority to the Executive Committee to make the necessary additions.

The President informed the Assembly that Mme Huet-Troué, who had served the Union for many years as Administrative Secretary, had asked to be relieved of her duties on grounds of health. She had served the Union with devotion and distinction for many years and had earned the deep gratitude of all concerned with the welfare of the Union. Mr King proposed that she should be appointed honorary member of the Union and that a gift should be made to her as a token of appreciation.

The Assembly approved this proposal.

\section{Future Meetings}

Mr King recalled that it had been the practice of the Union for many years to hold a meeting in conjunction with the International Conference of Dermatological Societies, which was next due to meet in Munich in 1967. The Secretary-General was asked to arrange such a meeting. The Assembly might give authority to the Executive Committee to decide upon the place of the next Assembly in 1967 in case the proposed arrangement proved impracticable.

The Assembly agreed.

Mr King informed the Assembly that during the coming year it might be possible to organize a regional meeting in Rome, on the invitation of Prof. Monacelli, Director of the University Department of Dermatovenereology, on the occasion of the inauguration of its new headquarters. Members of the Union would be notified in due course.

\section{Closure of the Assembly}

As there was no further business, the President thanked everyone who had contributed to the success of the meeting; the Secretary-General, the officers, the interpreters, and all the participants; he was very happy to see the meeting so well attended and looked forward to seeing all the participants again in 2 years' time.

The meeting adjourned at 5.45 p.m. 